\title{
Teachers' adoption of embodied learning digital games with an inclusive education approach: Lessons learnt from the INTELed project in Spain $^{\star}$
}

\author{
Alejandra Martínez-Monés ${ }^{1}$, Sara Villagrá-Sobrino ${ }^{1}$, Eva $\mathrm{M}^{a}$ Fernández \\ Faundez $^{1}$, and María Jiménez Ruiz ${ }^{1}$ \\ GSIC-EMIC research group, Universidad de Valladolid, Spain
}

\begin{abstract}
Embodied learning digital games have been used with success in the past to support students with special education needs, but their application by teachers in mainstream classes with an inclusive approach is still a challenge. This paper presents the results of a set of pilots in which a suite of embodied digital games was applied into pre-school and primary school classrooms. The findings of the studies provide insights into the conditions that facilitated and/or impeded the adoption of the technology by the participant teachers. These results are then elaborated to define a first set of strategies that could be used by third-party teachers to fulfill the same objectives, and to identify concrete design challenges for the application of embodied digital games in classrooms.
\end{abstract}

Keywords: Embodied digital games, Classroom management, Primary Education, Inclusive Education

\section{Introduction}

Embodied learning is a contemporary theory of learning which emphasizes the use of the body in the educational practice [2]. Inspired by this theory, there has been intensive research on the use of embodied digital technologies, with special focus on special education [1]. Existing research on embodied digital technologies has taken place in laboratory settings or one-to-one sessions in Special Education Units [4]. It is still a challenge how to integrate these embodied games and their associated pedagogical approaches into mainstream classrooms, specially

\footnotetext{
* This work is part of the INTELed Project [INnovative Training via Embodied Learning and multi-sensory techniques for inclusive Education] (Project 2017-1-CY01KA201-026733), which is co-funded by the Erasmus+ Programme of the European Union. This research has been partially funded by the European Regional Development Fund and the National Research Agency of the Spanish Ministry of Science, Innovation and Universities, under project grant TIN2017-85179-C3-2-R (SmartLET) and by the European Regional Development Fund and the Regional Council of Education of Castilla y Leon under grant VA257P18 (CASSUALearn))
} 
in inclusive educational contexts with students with and without disabilities [6]. To face this challenge, the EU-funded INTELed project ${ }^{1}$ aimed at training teachers in the use of embodied digital games, with a focus on promoting the inclusion of children with special education needs (SEN). The research question driving this work is: How can teachers adopt embodied learning games into their classrooms, considering principles of inclusiveness?

This paper reports the results of a study carried out on the INTELed pilots, where teachers, supported by the research team, designed and implemented activities supported by embodied digital games in their classes. The study followed a qualitative case study research design. The results of the study show how the teachers manage to overcome the obstacles they found to apply the INTELed methodology, and in which ways they integrated this new methodology into their classrooms: how they designed the lesson plans and how they enacted the activities. The results describe strategies that could be used by other teachers applying embodied digital games, and design challenges that have to be met to improve the introduction of these technologies into classrooms with an inclusive approach.

The structure of the paper is as follows: The following section reviews the main challenges of the application of embodied digital games to mainstream classrooms. Then, we present the context of the study, with information about the INTELed project and the conditions in which the pilot experiences were carried out. Then we present the results and their discussion. The paper finishes with conclusions and future work lines.

\section{Embodied digital games in the classroom: challenges}

Embodied learning constitutes a contemporary pedagogical theory of learning inspired in the principles of embodied cognition (EC), which emphasizes the benefits of the use of the body in the educational practice $[2,10]$.

From all the technologies that enable embodied learning, motion-based bodygesture technologies appear as some of the best suited to implement the principles of embodiment, based on the taxonomy proposed by [5]. Moreover, these technologies may have an advantage for their use by students with special needs, because full body interaction is more convenient for students that are not able of performing fine-grained gestures, such as the ones required by tablets and mice. These technologies are represented by commercial products such as Wii, Leap Motion and Kinect.

In a comparative study between these technologies [9], Kinect cameras were chosen as the most appropriate ones for their use in special education, due to their accuracy in identifying the body movements, the existence of an open API, the voice-recognition and RGB camera, and the fact they do not need calibration. Moreover, Kinect cameras are relatively affordable, and cheaper than other specific technologies that are used in special education. These reasons may

\footnotetext{
${ }^{1}$ http://www.inteledproject.org
} 
explain why most of the applications based on the idea of embodied learning are Kinect games [8].

The application of embodied digital games to children with SEN has provided initial evidence of success, although many issues remain unexplored about the effectiveness of this approach to enhance learning [4]. Additional challenges arise when addressing the application of these technologies, which are normally designed for one-to-one and personalized interaction, to formal education in schools. It is necessary to examine which are the best practices in the design and set up of learning environments that take full advantage of embodied learning [3]. Specific challenges are how teachers adopt these technologies, which are not of common use in the classroom; how do teachers integrate the tools in their curriculum; and how they setup and manage the classrooms to take full advantage of the embodied games. The work carried out in the INTELed project provided the opportunity to explore these issues in the four countries where the project was implemented. Next section describes the context of the study reported in this paper, based on the pilots that were set up in Spain.

\section{Context of the study}

\subsection{INTELed project}

The INTELed project is an EU-funded project that run between the years 2017 and 2019. Its main goal was to support in-service teachers in acquiring knowledge and skills about the use of embodied digital learning games for addressing the needs of SEN children in inclusive educational settings.

The project defined a teacher professional development (TPD) program, consisting of 4 phases. In the first phase ("teachers as learners"), the participant teachers received an initial training on the principles of embodied learning, including tools that support it in the classroom. In a second phase ("teachers as designers"), teachers acted as co-designers with the researchers, creating their lesson plans seeking to transfer the embodied learning pedagogy from theory into praxis. Then, the lesson plans were put in practice ("teachers as innovators") and finally, the pilots were evaluated with the help of the research team ("teachers as reflective practitioners").

Throughout these four phases, one researcher worked closely with the participant teachers, acting as a companion, and helping them in all the issues that appeared in the design and implementation of the pilots. She co-designed the lesson plans with the teachers, and gave them ideas about how to overcome the difficulties they found. This process was documented in a diary, which, as will be described later on, constitutes one of the most valuable data sources of the study.

\subsection{The local setting: the teachers' workgroup and the participating schools}

In Spain, the implementation of INTELed school pilots took place in three schools with pre-school and primary school education: CEIP Gómez Bosque, 
CEIP Antonio García Quintana, CEIP Francisco Pino. In the three of them, SEN students (i.e., pupils with moderate motor disabilities and/or learning difficulties) attend mainstream classes, and have a dedicated team of specialists that work in special units with them at certain times during the week.

In order to carry out the project, we established a collaboration with the Specific Team for Children with Motor Disabilities (EOEP for its acronym in Spanish). This team is composed of several specialists (physiotherapists, psychologists, language and hearing, etc.) that work in an interdisciplinary way with the children with SEN. In collaboration with the EOEP and the CFIE (the Centre in charge of in-service teacher training in our region) we set up in May, 2018 a "working group". This working group provided official recognition to the activities that the participant teachers and specialists carried out in INTELed.

The local coordinator of the working group was a psychologist that works in the EOEP, who could easily reach all teachers and specialists in the aforementioned schools. He launched two internal "calls for participation", one in May, 2018 , that served to initiate the proposal of the working group, and another one in September 2018, when the working group started to run, and the research team was preparing the first phase of the INTELed TPD. As a result of these two calls, an initial group of 25 teachers and SEN specialists joined the working group. From these 25 participants, 7 where teachers $(5$ pre-school and 2 primary school). They are the focus of this paper, as they are the ones that faced the challenge of integrating the embodied digital games in their classes with an inclusive approach.

This group of teachers worked semi-autonomously, organized into three subgroups (one for each school). For example, in one of the schools, the teachers set up regular meetings after the initial training to keep on learning about the tools and help each other in the implementation of the pilots. They were supported by one of the members of the research team, who was in permanent contact with them. She had a main role in helping the teachers achieve their goals and reach the implementation of the pilots.

\section{Pilots' setup}

As defined by the INTELed TPD, once the participating teachers had been introduced to the INTELed's pedagogical framework of embodied learning [7]

("teachers as learners"), they were asked to lead a set of school pilots in their classrooms ("teachers as innovators"). As an intermediate step, they had to design the lesson plans that were to be enacted in the classes ("teachers as designers").

\subsection{Design of the lesson plans}

From February to May 2019, the participant teachers and the research team worked together in the co-design of the lesson plans. The teachers were asked 
to integrate the embodied digital games they chose into their classes, in order to engage all the students (with and without disabilities) in the learning activities. These activities had to be related to learning goals defined in the curriculum. Each lesson plan included a description of the context on which it is applied (level, learning goals and competences); the connection with the curriculum (contents, assessment criteria); a description of the sessions and the activities to carry out in them; the resources needed; and, finally tips for its implementation ${ }^{2}$.

We carried out 4 pilots, involving 7 classrooms, 6 in-service and 3 pre-service teachers. Two of the pilots took place in pre-school education. One of them involved three classes in the same school (3, 4, and 5-year-old children), where the in-service teachers and a member of the research team proposed a similar design for all the classes; the second one involved a teacher of 5 -year-old children in a different school, who was able to design the intervention by herself. The other two pilots were carried out in primary education. One of them took place in $1^{\text {st }}$ and $4^{\text {th }}$ grade of Physical Education at a third school. A fourth pilot was led by a special education teacher who collaborated with a Primary School teacher of $3^{\text {rd }}$ grade to plan the educational design and the ways the SEN student could participate in the activity following an inclusive approach.

\subsection{Selection of the embodied learning tools}

One decision that had to be taken was to decide which application(s) would be used in the pilots. After analysing the repository of embodied learning tools that had been created by the INTELEd project ${ }^{3}$, the teachers chose to use Kinems learning games ${ }^{4}$. Kinems offers a suite of movement-based educational kinect games for children with special education needs, such as dyspraxia, autism, ADHD and motor difficulties. It aims to improve children's eye-hand coordination, visual perception, motor planning and execution skills, and can be used by children with and without disabilities, as the games help achieve different levels of school performance. In the underlying conceptual model of the tool, each school working with Kinems has a number of teachers. Each teacher is responsible of a number of students, for whom s/he must configure personalized sessions a priori. To that aim, the teacher can browse the whole set of games and possible configurations, or use a new feature that recommends a subset of games, based on the learning goals and the educational level. A session may contain one or several games with different configurations. During the enactment, the teacher selects the child, and the application runs the programmed session (which the teacher can modify on the fly in response to the evolution of the

\footnotetext{
2 Examples of two lesson plans can be found in https://platform.inteled.org/ wp-content/uploads/2019/07/Lesson-plan-1-Tika.pdf and https://platform. inteled.org/wp-content/uploads/2019/07/Lesson-plan-2-Do-like.pdf (In Spanish)

${ }^{3}$ https://www.inteled.org/repository/

${ }^{4}$ http://www.kinems.com
} 
session). The system monitors the performance of the child and provides reports to the teachers based on learning analytics.

Kinems provides a large offer of games. It was necessary to devote time to select the specific games that were to be used in the pilots. The teachers and the research team collaborated in order to find the most suitable ones for each class, taking also into account the characteristics of the SEN children who assisted to those classes. The final selection was composed of the following games:

Tikka Bubble: In this game, the child is asked to recognize matching pairs of objects, grab the corresponding bubbles at each side of one totem and bang them simultaneously at the center. This game helps a child to improve the way of coordinating both sides of the upper body, which is an indication that both sides of the brain are communicating and sharing information with each other. There are different categories of matching pairs which can be chosen. In our pilots, the teachers of pre-school education found it appropriate for the ages of their students and matching with the content about animals and plants they were developing at that moment. They used the Tikka Bubble game with different categories for each class. Tikka Bubble was also used with a more complex configuration in the pilot that took place in $3^{\text {rd }}$ grade, where the game was set up in this case so that students could identify the animal with an associated product (eg, Bee with Bee-wax).

Lexis: Lexis has the objective of becoming familiar with the spelling of words of different length and conceptual categories. This game is translated into Spanish, making it suitable for its application in our classrooms. The educator can choose the length of words or the conceptual category that will be shown to a child, the number of missing letters, as well as the time limit that might exist. Also, the educator can allow the child to see the picture of the given word thus helping the child to correlate the way an object is written. This game was used by the teachers in pre-school education with different configurations depending on the course (3-5 years old).

Do Like: Do like proposes interactive gross motor activities to help children improve their postural control and balance. With "Do Like" the child is asked to replicate a body movement or a sustained position by listening or reading a given instruction. The educator can choose from a variety of specified postures or movements. This game was used by the Physical Education teachers with $1^{\text {st }}$ and $4^{\text {th }}$ graders. In these cases, teachers employed Do Like game to help children improve their gross motor skills, body awareness, laterality, and balance. The game was configured with a different degree of difficulty for the two classes, with a specific profile for the SEN children in those classes.

\section{Methodology}

In order to address our research objective, we followed a qualitative case study guided by the following issue: How did teachers integrate the use of Kinems games based on embodied technologies into their classroom considering principles 
of inclusiveness? This issue involved studying which was the support needed by the teachers for the design of the activities; and which were the solutions proposed to overcome the difficulties they encountered.

The following data sources were used: the diary taken by the researcher during the co-design process and the implementation of the pilots; classroom observations during the enactment of the pilots and the interviews with the participant teachers that took place after the pilots.

These data were analysed with content analysis using a mixed approach, that combined predefined (etic) and data-driven (emic) categories that emerged during the coding process. The main two topics that structured the analysis correspond to the two themes derived from the research issue that have been mentioned above: T1. Support needed by the teachers; and T2: Solutions proposed.

\subsection{Results}

This section describes the main findings that emerged from the coding process. These findings are supported by excerpts of evidence from the data collected. To facilitate a better readability, these excerpts are codified in the text and their content is presented in Tables 1 and 2.

Support needed by the teachers The first topic explored up to which point teachers needed support, and what was the nature of their needs, both at design and enactment time.

Support at design-time. Right after the initial training, the working teams formed by teachers organized themselves to analyze the games, and generated templates in which they made explicit which were the most relevant aspects of the games for them: goals, students' characteristics, difficulties $\left([\text { Diary }]_{A}\right)$. This approach was deemed necessary by the teachers, as they reported that the knowledge acquired during the training had not been sufficient be aware of the possibilities offered by the tool $\left([\text { IntPhys }]_{A},[\text { IntPrimSchool }]_{B}\right)$.

The templates were geared to study which games were appropriate for which SEN children in each school, but they did not help the teachers find ways to integrate the games into their lessons $\left(\left[\text { Diary }_{B}\right]_{B}\right)$. This led to a higher involvement of the assistant researcher, who had to provide more advice and support to the teachers than expected $\left([\text { Diary }]_{C}\right)$. The assistant researcher maintained one to two co-design sessions with most of the participant teachers before the implementation. In these sessions, the research assistant facilitated the interchange of ideas and the reflection by the teachers, to i) make explicit the educational goals they pursued and the identification of the most appropriate games to reach them, and ii) provide the teachers information about the possibilities of the tool, depending on the characteristics of the students with and without specific education needs $\left([\text { Diary }]_{D}\right)$. 
Support at enactment. During the development of the pilots, the teachers perceived that the support provided by the external researcher, both at the technical and the methodological level was crucial to setup the activities in their classrooms $\left([\text { IntPhys }]_{C D}\right)$. In two cases, they also benefited from the presence of pre-service teachers during their internship, as a help to the design and implementation of the activities ([IntPrimSchool $\left.]_{E}\right)$.

Solutions and strategies to apply the tool in classrooms The teachers found different ways to address the problems that were posed at the outset of the project, that are discussed below:

Generic accounts for the classroom and specific for SEN students . Kinems offers personalized support for each child, which has proven to be appropriate for special education units. However, this feature was considered problematic for its application in classrooms with about twenty students each. The teachers stated that the time devoted to change the user for each child could affect the rhythm of the class and led to a loss of children's engagement. As a solution it was decided that the teachers selected the features of the corresponding game for each class, using a unique generic user, and created only a specific user with adapted settings for the special education students $\left([\text { Diary }]_{E}\right)$. This resulted in more dynamic sessions in which the students followed each other and could be almost autonomous using the tool.

This turnaround solved the problem of having to configure too many children profiles in advance and to change the user for each child, but has important drawbacks. It impeded the use of valuable features provided by the tool, especially the monitoring support, which could have provided useful information about the progress and performance of the students. However, these aspects of personalisation and monitoring were not at the focus of the teacher and they did not pay attention to them, even for the special education children, who did have a profile.

Work in stations. A second challenge was the fact that Kinems, as many other tools, is thought for individual interaction between the player and the game. When applied to a classroom with more than 20 children, this may mean that one child has to wait almost an hour to enjoy a few minutes with the tool. In response to this problem, the students were organized in small groups that worked in parallel activities. Thus, each class was structured in learning stations (or "corners") where the children had to rotate to carry out each one of these parallel activities. Students worked in small groups and when they had finished one activity, they passed to the next one ([IntPrimSchool $\left.]_{F}\right)$.

Provide clear directions. At the beginning of the session, each teacher explained the contents and the activities that would be done. In all the cases, the teachers provided very clear instructions to the students about how they had to interact with the tool, and the precision of the movements they had to make in order to avoid potential mistakes $\left([\mathrm{Obs}]_{A}\right)$. 
Specific focus on inclusion. An additional challenge, relevant for the project and for the classes where the pilots were implemented, was to promote collaboration, peer-help and the participation of all the students, conditions that were fundamental to guarantee inclusion in the class $\left([\operatorname{IntPrimSchool}]_{G}\right)$. In the aforementioned stations, the students were asked to work in groups (56 children) to learn from their peers, carrying out the activities at the same time as their mates who were working in front of the game. For example, in the Physical Education pilot, where the game used was DoLike, the children in each group were asked to do the same movements as the one in front of the Kinect camera) $\left([\mathrm{Obs}]_{B} ;[\text { IntPrimSchool }]_{G}\right)$. This strategy enabled the children that had problems interpreting the instructions of the game to learn from their peers $\left([\text { IntPrimSchool }]_{H I}\right)$ or by imitation when solving doubts $\left([\mathrm{Obs}]_{C}\right)$. In the case of the SEN students, the teachers decided to configure the program adapting the needs of each student. They were satisfied with this solution, and stated this allowed the SEN children feel more integrated into the classroom, as they had been able to play the same game as the others (which is not always possible).

\subsection{Discussion}

The results presented above help illuminate the issue addressed in the study, i.e., how did teachers integrate Kinems games into their classrooms with an inclusive approach.

The fact the tool offered many games and configuration possibilities enabled its use at different educational levels and for different learning goals. The flexibility of the tool enabled the SEN children to use the same games than the rest of the class, which was pointed out by the teachers as a key factor to favour inclusion.

However, this complexity also posed some problems. Teachers needed extra support to be able to identify the right games for their contexts. Even though they were encouraged to use the Kinems feature that helped to select the game and the configurations based on the learning goals, teachers did not use it. Their approach to get acquainted with the tool was to try to get familiar with all the games, and then, propose ways of applying them to their practice. This probed to be a very demanding task, that needed the intervention of the research assistant to help them select the games and the most suitable configurations. These results point out to the need of a longer and more focused initial training period, due to the complexity of the tool and the number of possibilities it provides to its users. Moreover, further work is needed to gain insight into the reasons why the goal-based selection approach was not followed by the teachers. This could be due to a lack of alignment between the goals offered by the games and the ones used in the Spanish context, or to deeper differences in the way teachers face the design of their classroom activities.

In spite of the difficulties, and thanks to the extra support given by the researcher, the teachers were eventually able to think of appropriate designs 
Table 1. Excerpts of data evidence from the Interviews. The code refers to the speciality of the interviewee (Physioterapist [IntPhys] or Primary School Teacher [IntPrimSchool])

\begin{tabular}{|c|c|}
\hline Code & Excerpt \\
\hline$[\text { IntPhys }]_{A}$ & $\begin{array}{l}{[\ldots] \text { I think we devoted quite a long time to the theoretical talks }} \\
\text { and too little time to the practical part }[\ldots] \text { but for the peo- } \\
\text { ple that did not know anything about the tools, perhaps the } \\
\text { practical part was too short to be able to put it in practice." }\end{array}$ \\
\hline$[\text { [ntPrimSchool }]_{B}$ & $\begin{array}{l}\text { In the training course I think we could have seen more games, } \\
\text { because it is the only way in which I can have an idea. I need to } \\
\text { know more games, which is what I need to work out. }\end{array}$ \\
\hline$[\text { IntPhys }]_{C}$ & $\begin{array}{l}{[\ldots] \text { At the beginning we were very negative and reluctant, be- }} \\
\text { cause we say it very difficult to bring the theoretical proposal } \\
\text { to the ground. And the poor lady [the researcher] found at the } \\
\text { beginning "no, this is not possible, this is not possible ...", and } \\
\text { eventually, thanks to her support and all the logistics and so on, } \\
\text { we have been able to implement the project. }\end{array}$ \\
\hline$[\text { IntPhys }]_{D}$ & $\begin{array}{l}\text { Well... the difficulties that schools have: a bad wi-fi network, a } \\
\text { bad Internet, bad computer logistics, etc. But, well, we have had } \\
\text { the luck that the university has solved it. }\end{array}$ \\
\hline$[\text { [ntPrimSchool }]_{E}$ & $\begin{array}{l}\text { We were lucky to count on two in-service teachers, and thanks } \\
\text { to their help we could bring INTELed to the gym (which seemed } \\
\text { not feasible at the beginning)." }\end{array}$ \\
\hline$[\text { [ntPrimSchool }]_{F}$ & $\begin{array}{l}\text { I think that if you do not work by stations or small groups, } \\
\text { I cannot think of any other way of carrying out one of these } \\
\text { activities in a mainstream classroom. }\end{array}$ \\
\hline$[\text { [ntPrimSchool }]_{G}$ & $\begin{array}{l}\text { I think that what has prevailed has been the focus on inclusion. } \\
\text { At least, as we have designed it. I wanted to use the Kinect in } \\
\text { Physical Education and to work cooperative learning. Then, it } \\
\text { was like ... how do I do to work on cooperative learning if in this } \\
\text { moment only one child was working in the game. Then, what } \\
\text { was difficult was to find a way so that they helped each other to } \\
\text { reach the final goal, which was the inclusion of all the children. }\end{array}$ \\
\hline$[\text { [ntPrimSchool }]_{H}$ & $\begin{array}{l}\text { To make it more collaborative, we have asked the classmates who } \\
\text { were in the Kinems station to make the same movements as the } \\
\text { one who was playing with the game. Moreover, we said that if } \\
\text { they saw somebody with difficulties, they could give them hints } \\
\text { to help them [...]. But that they should not be alone looking at } \\
\text { the screen. }\end{array}$ \\
\hline$[\text { [ntPrimSchool }]_{I}$ & $\begin{array}{l}\text { Then, maybe they give indications of how to improve, or the ones } \\
\text { that are doing the movement, so that their mate sees them and } \\
\text { has them a reference. I think they are the ones that help each } \\
\text { other. It is positive. Maybe they do not have the competitiveness } \\
\text { because they are out of the game, its not their turn. }\end{array}$ \\
\hline
\end{tabular}

that enabled all the children, with and without disabilities, use the tool and engage in the activities with success. Some of the ideas point out to patterns of 
Table 2. Excerpts of data evidence from the Observations and the Diary.

\begin{tabular}{|c|c|}
\hline Code & Excerpt \\
\hline$[\text { Diary }]_{A}$ & $\begin{array}{l}\text { Once they have tried it [the game] they will produce a template where } \\
\text { they will state: Minimum skills that the student has to have to play the } \\
\text { game; Goals of the game; Potential (SEN) students for which it applies; } \\
\text { Difficulties; Possibilities. }\end{array}$ \\
\hline$[\text { Diary }]_{B}$ & $\begin{array}{l}\text { We can observe in the teachers that the games are not responding to } \\
\text { the contents they teach. }\end{array}$ \\
\hline$[\text { Diary }]_{C}$ & $\begin{array}{l}\text { We are providing more help, they are not as autonomous as we would } \\
\text { have desired. }\end{array}$ \\
\hline$[\text { Diary }]_{D}$ & $\begin{array}{l}\text { (e-mail from the researcher to a teacher). In the template you wanted } \\
\text { to work with memory and logic reasoning with M. For you to have more } \\
\text { resources to work with, I propose you the following games: (Memory): } \\
\text { "UnboxIT", a game that [...] }\end{array}$ \\
\hline$[\text { Diary }]_{E}$ & $\begin{array}{l}\text { How do we apply games to a full class? Shall we create a profile for } \\
\text { each student? Do we have to exit and enter again each time a child } \\
\text { plays? The rest of the partners have solved this problem by using the } \\
\text { same account for all the class }[. . .] \text { although for the SEN students specific } \\
\text { profiles are created. }\end{array}$ \\
\hline$[O b s]_{A}$ & $\begin{array}{l}\text { The teacher explains how they have to put their hands, and how to hold } \\
\text { the object. The first time it is difficult for them, but motor control gets } \\
\text { better with time." }\end{array}$ \\
\hline$[O b s]_{B}$ & $\begin{array}{l}\text { XXX, the in-service teacher, is configuring the application and will } \\
\text { receive each group and explain to them what they have to do. He asks } \\
\text { the children that, while they are waiting for their turn, they may try } \\
\text { to follow the instructions given by the game". }\end{array}$ \\
\hline$[O b s]_{C}$ & $\begin{array}{l}\text { XXX is a child with intellectual and hearing disabilities. At the time } \\
\text { of performing the coordination activities with "Do Like", a classmate } \\
\text { helps him, telling him what to do. The second time he repeats the } \\
\text { exercise, he does it well. }\end{array}$ \\
\hline
\end{tabular}

use that could be generalized to other contexts, like the use of rotating stations that help to divide the whole class in groups of 4-6 children, where the children carry out different activities, but not all of them at the same time. This pattern was complemented with additional instructions, to enable help between peers, and learning by imitation, which probed to be helpful for the success of the activities, and for the inclusion of the SEN students.

\section{Conclusions}

The use of embodied digital games in classrooms is a promising educational approach, supported by the theories of embodied cognition. However, the existing technologies that have proven to be beneficial in one-to-one settings, need adaptation for their use in mainstream classrooms. Classrooms have conditions that differ from the special units were individualized support is the norm, and 
teachers have different ways of working than the specialists that treat children in those special units.

The pilots carried out in the INTELed project have given us the opportunity to explore the ways in which embodied digital games can be integrated in the classroom, with a focus on educational inclusion, and to identify challenges to reach that aim.

One outcome of the study is the identification of the use of "stations" as a good practice, that can be reused by other teachers in the future as a pattern. A second conclusion is that inclusive classrooms can benefit from configurable tools, that allow teachers adapt their content to the capabilities of the students. This probed to be true in our study, even though teachers were not able to use all the customization capabilities offered by the application.

The experience gained with these pilots points out to design challenges that remain unsolved. Further work needs to be done to deal with the trade-off between the full personalised support offered by the applications (with individual profiles defined by the teacher in advance) and the needs of providing a system as simple and efficient as possible so that teachers and students can integrate it into their classroom dynamics without additional burdens. Other design challenges, such as providing more facilities to adapt the content of the games to the curriculum, providing a kind of authoring tool for teachers, were also mentioned. This study should be put in contrast with the results obtained by the pilots in the rest of the countries that implemented INTELed, to find similarities and differences between the different educational contexts, and derive from them more generalisable results.

\section{Acknowledgements}

The authors want to thank Prof. Yannis Dimitriadis for his valuable feedback, and specially, to the teachers that worked in the INTELed project, and the students who eagerly participated in the activities carried out in the pilots reported in this paper.

\section{References}

1. Altanis, G., Boloudakis, M., Retalis, S., Nikou, N.: Children with motor impairments play a kinect learning game: First findings from a pilot case in an authentic classroom environment. Interaction Design and Architecture(s) Journal - IxD\&A, N 19, 91-104 (01 2013)

2. Anderson, M.L.: Embodied Cognition: A field guide. Artificial Intelligence 149(1), 91-130 (2003). https://doi.org/10.1016/S0004-3702(03)00054-7

3. Evans, M.A., Rick, J.: Supporting learning with interactive surfaces and spaces. In: Handbook of research on educational communications and technology, pp. 689-701. Springer (2014)

4. Fu, Y., Wu, J., Wu, S., Chai, H., Xu, Y.: Game system for rehabilitation based on kinect is effective for mental retardation. In: MATEC Web of Conferences. vol. 22, p. 01036. EDP Sciences (2015). https://doi.org/10.1051/matecconf/20152201036 
5. Johnson-Glenberg, M.C., Megowan-Romanowicz, C., Birchfield, D.A., SavioRamos, C.: Effects of embodied learning and digital platform on the retention of physics content: Centripetal force. Frontiers in Psychology 7, 1819 (2016). https://doi.org/10.3389/fpsyg.2016.01819

6. Kourakli, M., Altanis, I., Retalis, S., Boloudakis, M., Zbainos, D., Antonopoulou, K.: Towards the improvement of the cognitive, motoric and academic skills of students with special educational needs using Kinect learning games. International Journal of Child-Computer Interaction 11, 28-39 (2017). https://doi.org/10.1016/j.ijcci.2016.10.009

7. Martínez-Monés, A., Villagrá-Sobrino, S., Georgiou, Y., Ioannou, A., Ruiz, M.J.: The inteled pedagogical framework: Applying embodied digital apps to support special education children in inclusive educational contexts. In: Proceedings of the XX International Conference on Human Computer Interaction. pp. 1-4 (2019)

8. Martínez Monés, A., Sibrini, T., Villagrá Sobrino, S., Jiménez, M., Georgiou, Y., Ioannou, A.: O1- t3. a collection of existing ict multi-sensory educational resources and tools for learning and assessment for the support of sen students. Tech. rep., INTELed Erasmus+ Project. European Commission (2018)

9. Ojeda-Castelo, J.J., Piedra-Fernandez, J.A., Iribarne, L., Bernal-Bravo, C.: KiNEEt: application for learning and rehabilitation in special educational needs. Multimedia Tools and Applications pp. 1-27 (2018). https://doi.org/10.1007/s11042018-5678-1

10. Wilson, M.: Six views of embodied cognition. Psychonomic bulletin \& review 9(4), 625-636 (2002) 